\title{
Airborne lidar remote sensing applications in non-forested short stature environments: a review
}

\author{
R.W. Kulawardhana, S.C. Popescu, R.A. Feagin
}

Kulawardhana R.W., Popescu S.C., Feagin R.A., 2017. Airborne lidar remote sensing applications in non-forested short stature environments: a review. Ann. For. Res. 60(1): 173-196.

Abstract. Lidar (light detection and ranging) remote sensing technology provides promising tools for $3 \mathrm{D}$ characterization of the earth's surface. In ecosystem studies, lidar derived structural parameters relating to vegetation and terrain have been extensively used in many applications and are rapidly expanding. Yet, most of the lidar applications have focused on tall, woody vegetation in forested environments and less research attention is given to non-forest, short stature vegetation dominated ecosystems. Similar to the lidar developments in forestry, novel methodological approaches and algorithm developments will be necessary to improve estimates of structural and biophysical properties (i.e. biomass and carbon storage) in non-forested short stature environments. Under changing climate scenarios, the latter is particularly useful to improve our understanding of their future role as terrestrial carbon sinks. In an attempt to identify research gaps in airborne lidar remote sensing application in short stature vegetation studies, in this review article we provide a comprehensive overview on the current state of airborne lidar applications. Our focus is mainly on the levels of accuracies and errors reported, as well as the potentials and limitations of the methods applied in these studies. We also provide insights into future research needs and applications in these environments. Keywords airborne lidar, short stature vegetation, terrain, errors and accuracies

Authors. Ranjani W. Kulawardhana (ranjani.w.kulawardhana@jsums.edu) Department of Biology, Jackson State University, 1400 Lynch Street, Jackson, MS, USA; Sorin C. Popescu, Rusty A. Feagin - Department of Ecosystem Science and Management, Texas A\&M University, 1500 Research Parkway, Suite B 221, TAMU 2120, College Station, TX 77845, USA.

Manuscript received July 13, 2016; revised December 12, 2016; accepted December 19, 2016; online first January 19, 2017.

\section{Introduction}

Lidar remote sensing applications in forestry have been reported since 1980s (Nelson et al.
1988). Yet, most of the lidar applications have focused largely on tall, woody vegetation-dominated forested environments, more specifically conifer, temperate broadleaf and plantation 
forests (Straatsma \& Middelkoop 2006), while less research attention is given to non-forest, short stature environments. As short stature environments, we identify a variety of ecosystems including rangelands (i.e. grasslands, deserts, savannas, and pasture lands), wetlands (bogs, fens, swamps, and marshes), and polar ecosystems (tundra and taiga). Short stature vegetation in these ecosystems plays a key role in many important ecological processes. For example, nearly $50 \%$ the world's land area is covered by Rangelands (i.e. grasslands, shrublands, deserts and tundra) and contributes to more than a third of terrestrial C reserves (Allen-Diaz, 1996).

Even in forested ecosystems, the understory herbaceous vegetation plays a key role in determining forest structure and composition. Ecosystem products and services they offer includes: increased biodiversity (Halpern \& Spies 1995), provisioning of forest fuel loads (Arno 2000) and nutrient cycling (Gilliam 2007). Further, the presence, abundance and diversity of the forest understory serve as indicators of forest ecosystem health (Schulz et al. 2009, Suchar \& Crookston 2010); contribute to building forest biomass and carbon (C) stocks and fuel loads (Arno 2000); and shape future forest structure and diversity (Legare et al. 2002). Yet, only a few studies reported the contributions of understory vegetation to forest ecosystem biomass and carbon (C) stocks and thus have eluded forest carbon quantification at larger spatial (i.e. regional to global) scales. Thus, in this review, we also include studies focused on forest understory comprised of mixed herbaceous and short woody vegetation.

Measurements relating to structural arrangement of vegetation canopies are of critical importance in characterizing landscapes. For example, information relating to canopy structure provides a substantial amount of information on condition and functioning of vegetated ecosystems. However, conventional, field based methods for characterizing vegetation structure have significant limitations, in particular 174 at larger spatial scales (i.e. regional to global). Over the past two to three decades, there has been an enormous growth in availability of remotely sensed data leading to development of a wide variety of remote sensing applications in vegetation studies. The majority of these applications however, have largely been dependent on rapidly and freely available data from passive, optical remote sensing systems (i.e. multispectral data from aerial photography and satellite sensors). However, passive optical remote sensing data are largely affected by signal attenuation due to poor atmospheric and background conditions. Further, their signals are originated largely from the electromagnetic energy reflected from the uppermost canopy layers and therefore less sensitive to vegetation structure (Steininger 2000). Thus, passive optical remote sensing data have significant limitations in vegetation studies, more specifically for characterizing their 3D structure and related vegetation biophysical parameters (i.e. vegetation biomass and carbon stocks). More specifically, in short stature environments multispectral remote sensing measurements from these passive optical devices are further limited by different factors such as signal scattering from multiple layers of vegetation, bright soil background, relatively open vegetation and spectrally similar \& / indiscriminate targets (Jakubauskas et al. 2001, Mirik et al. 2007, Okin et al. 2001, Smith 1997). Further, the sensitivity and accuracy of these systems decline with increasing vegetation biomass and canopy cover (Drake et al. 2002).

Lidar remote sensing also uses NIR wavelengths in vegetation and terrain scanning. Laser interactions with vegetation and ground objects and thus, the recorded data (i.e. lidar intensity values) are therefore still affected in many similar ways. However, the ability of lidar data to provide accurate representations on three dimensional arrangement of vegetation canopies as well as sub-canopy topography (Blair \& Hofton 1999, Dubayah \& Drake 2000, Harding et al. 2001), and their ability to provide direct measurements on canopy pa- 
rameters (i.e. height, canopy diameter, cover, LAI) are added advantages in vegetation and terrain studies. Further, lidar devices can provide sub-meter accuracy levels in the estimates of vegetation structural properties including tree heights (Straatsma \& Middelkoop 2006) and parameters relating to forest density such as stem number (Lefsky et al. 1999, Næsset \& Bjerknes 2001), stem diameter (Drake et al. 2002, Næsset 2002, Lin et al. 2016), timber volume (Nilsson 1996, Nelson et al. 2009) or basal area (Means et al. 1999) at a range of scales appropriate for landscape to ecosystem level assessments. Further, the ability of lidar data to estimate vegetation biophysical characteristics such as biomass and canopy cover with higher accuracy levels is superior to passive multispectral remote sensing. This is of significant importance over high biomass ecosystems where spectral signatures from passive optical remote sensors have shown to deteriorate or saturate (Drake et al. 2002, Means et al. 1999). More recently, an increasing number of studies incorporated lidar-derived canopy parameters in forest biomass prediction models (Boudreau et al. 2008, Drake et al. 2002, Lefsky et al. 2005, Lin et al. 2011, 2016, Montesano et al. 2014, Popescu et al. 2011, Zolkos et al. 2013). The main purpose of this review article is to provide a comprehensive overview on the current state of airborne lidar applications in short stature environments. In this review, we first provide an overview on the impacts of vegetation more specifically in short stature environments to discuss their effects on laser scanning and lidar data. The later part of this review focuses on 3 broad categories of airborne lidar applications in short stature environments for: 1) vegetated terrain estimates \& characterization; 2) land use land cover (LULC) characterization: and 3) estimates on vegetation biophysical parameters. In each of these sections, we focus mainly on the levels of accuracies and errors reported, and potentials and limitations of the methods applied. We also attempt to provide insights into future research needs and applications in these environments. Thus in this review, we do not attempt to provide comprehensive details on lidar technology, rather refer the readers to other articles (i.e. Baltsavias 1999, Petrie \& Toth 2008, Popescu 2011, Wehr \& Lohr 1999). Further, we focus on airborne lidar applications and do not attempt to discuss any applications using other lidar systems (i.e. space-born lidar or ground scanning) mainly due to their very limited applications reported in these short stature environments. For comprehensive reviews on airborne laser scanning of forests and other natural environments, readers are referred to Lim et al. (2003) and Heritage and Large (2009), respectively.

\section{Effects of vegetation on laser scanning and lidar data}

\section{Effects on terrain estimates}

Accuracy of lidar derived DEMs is known to affect largely by physical structure of vegetation. For example, erect form, and high density and homogeneity of vegetation heights have known to increase DEM errors over vegetated terrains (Hopkinson et al. 2004). Vegetation overstory can also affect the density of lidar points returning from the nearby ground surfaces (i.e. ground points, Hodgson \& Bresnahan 2004). Further, the attenuation of laser beam irradiance passing through a canopy is directly affected by the characteristics of vegetation that include density, size, horizontal and vertical distribution, spectral and roughness properties of foliage, woody elements and ground cover beneath canopy. Thus, for a comprehensive evaluation on vegetation influence on lidar quality, it is necessary to understand the basic principles relating to laser interactions with the reflecting surfaces that include vegetation overstory. In any type of vegetated terrain, it is crucial to know the height of vegetation from where a lidar pulse is reflected. For example, in dense vegetation over tidal flats and salt marshes, this height correlated to one-half of the vegetation height (Populus 
et al. 2001). The average depth that lidar can penetrate through marsh vegetation is also reported as 0.03-0.1m (Sadro et al. 2007). However, over densely vegetated areas, as in the case of most herbaceous environments, further research is necessary to determine whether a laser pulse is returning from the bare earth or the above-ground vegetation.

In general, a systematic upward shift in lidar heights and thus a positive bias in lidar derived elevation estimates is expected as a result of laser beams returning from above the bare ground or if a mixed signal is returned from ground and vegetation surfaces (Gorte et al. 2005, Gopfert \& Heipke 2006, Rosso et al. 2006) (Sadro et al. 2007, Toyra et al. 2003). This vegetation dependent positive bias may correlate directly with vegetation characteristics including plant height, density (Gopfert and Heipke 2006, Populous et al. 2001, Toyra et al. 2003) and vegetation type (Gopfert \&Heipke 2006). Shape and orientation of plant leaves contribute to changes in foliage profile and thereby influence vegetation-laser interactions and thus laser penetration characteristics. Broadleaf dicots that are generally characterized by oval-shaped and horizontally orientated leaves can attenuate laser beam irradiance passing through the canopy more readily leading to prompt reflections of the signals back to lidar sensors (Ni-Meister et al. 2001). For example, $80-90 \%$ canopy cover result only $10 \%$ of the lidar pulses to reach ground surface (Cowen et al. 2000) whereas in coastal salt marsh environments proportion of the lidar pulses that reached ground surface was as low as 3\% (Sadro et al. 2007). These findings indicate that vegetation cover intercepts a relatively large proportion of lidar pulses and, thus only a few reach ground. Thus, increasing vegetation cover can lead to a sparse distribution of lidar points returning from ground surfaces beneath vegetation cover. Accurate classification of lidar returns as vegetation and ground returns is critical for the accuracy of terrain estimates using lidar. This classification can be increasingly challenging when the proportion 176 of lidar returns from the ground were small or absent, or when the vegetation was not tall enough to enable accurate detection of ground vs vegetation returns by the sensor (Gopfert \& Heipke 2006). Leaf loss can potentially increase the likelihood of lidar signal originating from closer to ground surface (Hodgson \& Bresnahan 2004, Su \& Bork 2006) and thus lidar data acquisition during leaf-off conditions is generally recommended for improving accuracies of terrain estimates where possible (Zlinszky et al. 2014). In contrast, angular or nearly vertical leaf orientations and needle like leaf blades of monocots, which is the dominant vegetation in grassland environments, facilitate increased laser penetrations through the canopy and to ground surfaces and can increase the proportion of lidar returning from ground and thereby may contribute to improving the accuracies of lidar derived ground estimates. Laser interactions with this type of vegetation however, tends to be more complex as this canopy architecture could cause repeated bouncing back and forth of incoming lidar signals within the grass canopy. For example, this nature of laser interactions may delay lidar return signal emanating from grasslands (Su \& Bork, 2006) leading to considerable underestimation of ground elevations. With taller vegetation, this problem can even become more prominent, as the distance of laser beam through different layers of vegetation becomes longer. If we assume a uniform vegetation structure in every layer, probability for laser energy to get absorbed or reflected before reaching ground is lower in relatively shorter vegetation. Thus if a uniform vegetation density along vertical profile of the canopy is assumed, an increase in negative bias of elevation estimates can be expected with increasing vegetation heights. However, leaf densities in almost all vegetation canopies vary significantly with canopy height and thus make it more challenging to quantify this bias in elevation estimates using lidar.

Several studies in short stature environments indicated that proximity to the nearest ground 
lidar point is affected by vegetation interception effect (Hodgeson et al. 2003, Sadro et al. 2007, Yang et al. 2010) and therefore correlate with land cover category (i.e. scrub/shrub, forest, grass). In addition, within landscapes where vegetation is structurally more complex (i.e. thin shrub/ scrub lands and mixed vegetation types), and very short-statured (i.e. grasslands), lidar systems may not be able to detect centimeter-level height differences between vegetation and ground surface (Bowen \& Waltermire 2002) and may decrease accuracies of lidar derived DEMs (Hodgson \& Bresnahan 2004, Reutebuch et al. 2003). However, studies in short stature environments have reported variable effects of vegetation while some studies indicated minimum or no significant vegetation effects (Montane \& Torres 2006) on the accuracies of terrain estimates using lidar.

\section{Effects on vegetation estimates}

Limited lidar applications in short stature environments are attributed to two main aspects of their vegetation characteristics. First, dense vegetation, characterized by relatively less openings in vegetation cover limits laser penetration into the ground (Toyra et al. 2003), making terrain and thus vegetation height estimates increasingly challenging and less accurate (Chassereau et al. 2011, Hopkinson et al. 2005). Second, relatively shorter vegetation and low variation in vegetation height and canopy characteristics along vertical profile of the canopy erode predictability of lidar derived variables in vegetation estimates ( $\mathrm{Li}$ et al. 2015, Rosso et al. 2006, Wang et al. 2007). Theoretically in lidar remote sensing, vegetation structure can be better characterized using information provided by both first and last returns recorded for each emitted laser pulse. However, the ability of lidar data to characterize vegetation structure is determined by the sensors ability to detect height differences between vegetation and ground returns and demands two conditions: height differences between returns from vegetation and ground surfaces are larger than 1) sensor's detection limits, and 2) vertical errors associated with each of the returns (Rosso et al. 2005). In short stature vegetation canopies first and last returns (generally coded as vegetation and ground returns, respectively) are often too close in both space and time making the separation of laser returns from ground and non-ground surfaces including vegetation increasingly challenging. Ability of a lidar sensor to separate returns that are too close in time is determined by the reset time (also known as range resolution) of the sensor. For a successful separation of two neighboring targets along pulse path, the minimum height difference between two targets should correspond to this reset time. Most lidar systems are designed with a reset time of 8-10 nano seconds and thus enable a range separation of 1.2 to $1.5 \mathrm{~m}$ (Popescu 2011). As a consequence, in short stature vegetation canopies, there is a greater probability for reflected energy from vegetation and ground surfaces to become comingled. Thus in relatively shorter vegetation, depending on the reset time of the sensor and the height difference between ground and top of the vegetation from where laser returns are reflected, the system may not be able to discern more than one return (Schmid et al. 2011) or can result in practically identical first and last returns (Wang et al. 2007). Over some herbaceous environments (i.e. grasslands and coastal environments), the combined effect of uncertain separation of lidar returns and intrinsic instrument errors may lead to unacceptably large estimation errors in vegetation height as well as terrain estimates relative to their typically small topographic relief and small vegetation heights (Rosso et al. 2006, Wang et al. 2009).

Over sparsely vegetated landscapes vegetation heights may be calculated as the height differences between first and last returns, while ground estimates can be derived based on last returns. The basic assumption here is that first returns are reflected from top of the canopy surfaces, while last returns are from the ground. There is no straightforward meth- 
od that can determine the depth of laser pulse penetration before reflecting back to the sensor. Over sparsely vegetated environments (i.e. grasslands) laser pulses do not reflect from the absolute top of every stem it contacts, but rather some distance within canopy leading to underestimation of vegetation heights. The depth of the canopy from where the laser pulses reflect is governed by the amount of canopy cover as the reflection is produced when a threshold density of stems is sufficient to cause a reflection. (Hopkinson et al. 2005). Furthermore, in sparsely vegetated environments, as in the case of most dry land ecosystems, fewer vegetation returns (as compared to densely foliated forested ecosystems) are recorded (Li et al. 2015, Mitchel et al. 2015, Rango et al. 2000, Ritchie et al. 1992, 1996, Weltz et al. 1994) and may not provide sufficient details to capture relatively larger spatial variation in vegetation surfaces, which may lead to increased errors in vegetation estimates. On the other hand, when the plant cover is dense, these pulses may not be able to penetrate all the vegetation layers and reach the ground surface (Cobby et al. 2001, Estornell et al. 2010, Gopfert \& Heipke 2006, Hodgson et al. 2005, Raber et al. 2002, Riano et al. 2007). These laser interactions will collectively lead to misrepresentation of vegetation characteristics in short stature environments.

\section{Lidar applications in short stature envi- ronments}

Over the recent past, a variety of lidar applications have been reported even in the short stature environments. In this review, we identify three broad categories of studies on airborne lidar applications in short stature environments for: 1) estimating terrain elevation; 2) mapping and characterization of landscape and vegetation; and 3) estimating vegetation biophysical parameters (height, cover and biomass). In the following sections, we provide comprehensive overview on the findings of these studies. We 178 focus our discussions mainly on the levels of accuracies and errors reported as well as the limitations and potentials of the methods applied.

\section{Applications for vegetated terrain estimates and characterization}

Mapping terrain elevation has been the primary focus of most lidar collections over short stature non-forest environments. Over the past decades, there has been a significant increase in the use of lidar data for deriving DEMs (Gesch 2007) and there is an extensive literature on terrain characterization using lidar. Vegetation cover can significantly affect laser penetration properties and in turn the accuracy of terrain estimates over vegetated landscape. As such, this review only discusses aspects of terrain extraction as they relate to vegetation characteristics of short stature environments.

\section{Methods and algorithms}

To determine surface elevations using laser scanning, it is necessary to separate laser pulses reflected from ground and vegetation or other objects (Kilian et al. 1996, Kraus \& Pfeifer 1998, Vosselman 2000). Separation of lidar returns from ground and vegetation surfaces is performed using a combination of automated and manual procedures that utilize geometric and topologic relationships of 3D data. Automated methods perform neighborhood operators that iteratively identify the lowest points within a predefined search window as "ground" returns. In subsequent iterations these 'ground returns' will further refine by adding additional returns that are also "low" or exhibit some angular deflection from a surface modeled by the previously identified set of points. Further processing of selected data points can include visual and statistical processing steps that further remove returns from vegetation above the ground surface. Latter process can be locally adaptive and subjective (Hodgson \& Bresnahan 2004). Most of the filter algorithms cal- 
culate a measure of discontinuity based on a local neighborhood (Sithole \& Vosselman 2004), while some adopt slope based filters (i.e. Vosselman 2000). Local neighborhood and slope based filtering algorithms perform well in smooth landscapes, however produce increased errors in rough terrain (Vosselman 2000, Sithole \& Vosselman 2004), dense and complex vegetation (Hladik et al. 2013), and steep slopes (Kraus \& Pfeifer 1998).

Common filter algorithms are capable of removing points reflected from higher vegetation and thus can improve accuracies of bare earth models, but fail to detect short vegetation, which is not significantly higher than surrounding bare ground (Chassereau et al. 2011). Thus in short stature environments, specifically in herbaceous cover, vegetation and ground could not be differentially mapped by simple filtering. In these environments incorporation of lidar variables that are correlated with vegetation characteristics (i.e. local variance in laser pulse height) has been able to improve elevation estimates using lidar (Table 1, Supp. Info.). For example, empirical relationships between standard deviation of lidar elevation and vegetation height have been applied to calculate surface elevations (Coby et al. 2001, Davenport et al. 2000). Point labeling (Cobby et al. 2001) and land segmentation (Raber et al. 2002) algorithms have also reported to be superior to common algorithms. Some of the complex point labeling algorithms incorporated slope limits during point labeling (Schmid et al. 2011). For multi-story environments, and complex terrains, use of more "intelligent" algorithms (rather than simple automated algorithms) and lasers with shorter pulse lengths have also been suggested (Hodgson et al. 2003). These algorithms applied differential filtering based on the information available on land cover and/ vegetation characteristics and thus improved accuracies of lidar derived elevation estimates. Even with this differential filtering, elevation accuracies still decreased with increasing vegetation cover (Chassereau et al. 2011, Ritchie et al. 1996), partly due to the ineffectiveness of filter methods in removing lidar returns originated from above the ground surface in particular when only a few or no ground points available within analyzed area.

Inclusion of data other than lidar (i.e. multiand hyper-spectral data, land cover classifications, aerial images, and field observations -Table 2, Supp. Info.) is also reported as an attempt to capture variations in ground cover. For example, photogrammetric processing techniques improved accuracies of lidar derived terrain estimates (Carter et al. 2001, Hicks et al. 2002, James et al. 2007, Lane 2000) largely by supplementing detection of break lines and stream edges where sudden changes in terrain exist over low lying coastal marshes (Adams \& Chandler 2002), and under highly heterogeneous vegetation (height and cover) conditions (Montane \& Torres 2006). These findings thus indicate the necessity of improved methods for characterizing terrain, in particular over complex landscapes. Several other studies therefore adapted different smoothing techniques such as moving-window smoothing (Wang et al. 2009, Yang 2005). However, such filtering is recognized to diminish micro topographic structures in complex terrain conditions as in salt marsh environments and would probably lead to complete loss of narrow channel structures (Lohani \& Mason 2001). In such conditions, filtering algorithms can be applied only to the specific areas of interest and should exclude the areas of sudden terrain irregularities (Wang et al. 2009).

Many algorithms that have been developed for the separation of ground and non-ground lidar returns are based on two assumptions: 1) topographic relief to be relatively gradual; and 2) ground is locally the lowest reflecting surface. Hence, the lowest lidar point in a local neighborhood (within a specified window) is considered to have fully penetrated vegetation and reached the ground (Sankey \& Bond 2011; Schmid et al. 2011, Struetker \& Glenn 2006). However, the dimensions of filtering window determine the levels of exclusion of lidar data 
and smoothing, and therefore can be a key determinant of the accuracies of the derived DEMs. For example, significant differences are reported in the RMSEs in elevation estimates derived using different window sizes in coastal marshes (Kulawardhana et al. 2014), grasslands (Ritchie et al. 1996), croplands (Coby et al. 2001), and shrub lands (Struetker \& Glenn 2006). Some of these findings revealed increasing challenges in short stature environments and indicated that even last lidar returns filtered using the smallest window size were returning from inside vegetation rather than from the ground surface (Kulawardhana et al. 2014). This type of laser-vegetation interactions often results in collection of lidar point elevations that closely resemble a flat surface consistent with the ground surface (Gopfert \& Heipke 2006), more specifically in dense vegetation cover.

Interpolation of lidar points to raster surface is generally identified as a measure for reducing vertical error in lidar derived elevation estimates (Hopkinson et al. 2004, Zlinszky et al. 2014). Before interpolations selective classification of lidar returns as ground and vegetation returns can improve lidar derived elevation estimates. This classification however, should be performed considering variations in both terrain and vegetation cover (Morris et al. 2002, Montane \& Torres 2006, Rosso et al. 2005; Sadro et al. 2007, Wang et al. 2009). Filtering of laser returns based on their timing of returns (i.e. first or last returns) rather than their relative positioning on the vertical domain is also a common practice. For example, DEM interpolations using local minima of only the first returns have proven superior results over use of all the returns within sage brush dominated terrain (Struetker and Glenn 2006) as this approach tends to minimize potential problem of multiple returns originating from similar heights of the terrain. Such filtering would be effective in relatively short vegetation, where multiple returns originating from similar heights may not be recorded as separate returns in the lidar systems, particularly if the 180 sensor's signal detection threshold is too low (Hodgson et al. 2003). This method however may not be appropriate for dense canopies. If the canopy is too dense, the number of ground returns available within the local window may not be sufficient to generate an accurate ground surface. There would also be a balance between maximum canopy cover and terrain variability. For example, over a gentle terrain, even with a relatively fewer number of ground points an accurate interpolation of the surface could be generated (Gong et al. 2000; Raber et al. 2002), while over a rugged and variable terrain increased number of ground points and therefore more canopy openings will be necessary, which can be rather challenging in most short stature non-forest environments.

Interpolation of raw or filtered lidar heights is performed using specified window sizes. In this process, the size of the filtering window, further determines the levels of smoothing, terrain irregularities retained in derived DEMs and thus their levels of accuracies (Wang et al. 2009). In general, smaller neighborhood smoothing significantly improve derived DEMs while interpolations using larger filtering window sizes can lead to lower accuracies of elevation estimates using lidar. The size of the filtering/ smoothing window however, needs to be determined based on the amount of information available in the data (i.e. lidar point density). In general, higher lidar point densities may allow DEM interpolations using smaller window sizes as they provide more information (i.e. points) for the interpolation. Simple spatial-interpolation techniques, such as IDW and natural neighbors can be recognized as traditionally preferred methods ( $\mathrm{Su}$ $\&$ Bork 2006). However, advanced techniques (e.g., kriging, splines, decimation, and break lines) may be more appropriate in specific situations. For example, kriging with a trend model may be more accurate for lidar data with decreased point densities (Lloyd \& Atkinson 2002). 
Errors and accuracies of lidar derived terrain estimates

Most lidar data are available with vertical accuracies of about $\pm 0.15 \mathrm{~m}$ when compared to surveyed ground points (Hetherington 2009), and with a comparable root mean square error (RMSE) for bare earth returns, while the best accuracy levels are achievable only under the most ideal circumstances (e.g., for low altitude areas, flat terrain, minimal or no surface vegetation or obstructions, much human analysis, etc.). Some empirical studies suggest accuracies of $\pm 0.25 \mathrm{~m}$ or larger as more realistic for large scale mapping applications in complex terrain and vegetation conditions as in the case of herbaceous environments (Hodgson \& Bresnahan 2004, Su \& Bork 2006). In general, vertical accuracy of lidar derived elevation estimates over open-terrain conditions is used as a measure of overall quality of lidar data collection and post-processing, while the errors over vegetated/ constructed areas can help understanding error contributions from laser interactions with vegetation and other ground objects. Most accuracy assessments provide vertical RMSEs, and overlook potential horizontal errors, which are typically greater than vertical errors, but can be difficult to assess in lidar datasets. This difficulty is due to the inability for precisely locating, or the lack of distinct topographic features on elevation surfaces that are necessary for such tests. Due to this reason horizontal accuracies are generally derived based on the factors relating to lidar system characteristics including flying height and angle relative to the ground surface. Vertical accuracies of the lidar derived elevation estimates can be evaluated either by comparing: 1) original lidar heights or 2) interpolated surfaces to reference elevations measured using ground surveys (Table 1, Supp. Info.). Although the first approach eliminates interpolation error, elevation accuracies still rely on the GPS accuracy, and thus our ability to locate lidar points precisely on the ground.
Total error associated with elevation estimates can be classified into various components. These generally include, in order of decreasing importance, errors from lidar system measurements, interpolation errors, horizontal displacement errors, and surveyor errors (Hodgson \& Bresnahan 2004). Several efforts have been made to identify, understand and where possible, to reduce these errors and their sources, while some others attempted to identify and explain the influence of specific ground characteristics such as vegetation type and density (Narayanan \& Guenther 1998, Ni-Meister et al. 2001), slope gradient (Bufton 1989), and other external factors such as off-nadir sampling angle (Tsutsui et al. 1998). While the majority of studies in short stature environments indicated a systematic upward shift in lidar heights (positive bias) ranging from 0.02 to $0.72 \mathrm{~m}$ a few reported a negative bias in lidar-derived elevation estimates (Table 1, Supp. Info.).

Collecting enough lidar returns from the ground, which is critical for mapping elevation and subsequently terrain slope/aspect is a major challenge in dense herbaceous environments. Adjusting specifications of lidar collections (i.e. flight height, pulse rate, sensor type, and field of view) to: 1) emit a large number of laser pulses; and 2) limit the area coverage of laser pulse interactions (i.e. smaller laser pulse footprints) and thereby to increase the likelihood of laser pulses that penetrate vegetation to reach the ground can increase the proportion of laser pulses returning from ground. In the case of aerial lidar, higher lidar point densities can be achieved by changing flight specifications (i.e. lower flying altitude, reduced speed). Effects of lidar collection and system parameters (e.g., flying altitude, laser instrument) on the sensitivity of lidar data and accuracies of elevation and vegetation estimates derived using them has not been rigorously researched, and thus indicate the necessity of future research focused on these aspects. Findings of some previous studies however, have indicated varying effects of ground and vege- 
tation characteristics on horizontal and vertical accuracies of acquired lidar data, as well as the accuracies of elevation estimates derived using them. For example over herbaceous understory in a forested area (Cowen et al. 2000) and mixed vegetation environments (Hodgeson et al. 2005), strong linear relationships have been reported between density of lidar points returning from ground and percent canopy cover. These findings however, did not explain if the accuracies in elevation estimates were affected by the point density alone. Few other studies, did not establish such relationships, however attributed greater errors in elevation estimates to lower point densities of lidar data acquired over sagebrush dominated landscapes (Glenn et al. 2011, Mitchell et al. 2011). Thus if the larger errors in dense vegetation cover is primarily attributed to data limitations, increasing lidar posting density through changing flying and laser scanning attributes (higher pulse rates and lower AGLs) may improve the accuracies of lidar derived elevation estimates.

Early work in topographic mapping relied on Koppe's formula for estimating elevation errors attributed to covariation of horizontal error and slope (Maling 1988). According to this formula, for any observation with a constant error in horizontal location, elevation error increases as the slope increases. This remains true and even become more problematic in estimates of terrain using lidar, more specifically when large footprint lidar data is used over extended geographic areas as in the case of regional to global scale elevation estimates using space-borne lidar (Lee et al. 2011, Lefsky et al. 2007). Local scale studies over herbaceous environments indicate varying effects of increasing slopes in the accuracies of lidar derived terrain estimates (Adams \& Chandler 2002, Bowen \& Waltmire 2002, Estornell et al. 2010, Hodgson \& Bresnahan 2004, Spaete et al. 2011). Contrasting findings have also been reported with minimal or no slope effect on the accuracies of lidar derived elevation estimates (Hodgson et al. 2005, Montane \& Torres 2006). Over the areas of mixed vegetation and 182 varying slopes the effects of slope on elevation accuracies are confounded by varying effects of vegetation (Hodgson \& Bresnahan 2004, Hodgson et al. 2005, Spaete et al. 2011). Other than the slope, increased terrain unevenness/ irregularities as reflected in micro topographic variations are also identified to increase elevation errors (Asselman 2002, Chassauereu et al. 2003, Su \& Bork 2006).

\section{Applications for vegetation and land use/ land cover (LULC) characterizations}

LULC classification studies in short stature environments indicate that the synergy of lidar and optical data improved classification accuracies as compared to using either of these data alone (Table 2, Supp. Info.). This improvement is achieved by exploiting spectral signatures and information relating to three-dimensional structure of vegetation canopies provided by multispectral and lidar data, respectively. More specifically, use of lidar data in classification algorithms have helped overcome some of the limitations associated with spectrally similar vegetation types, mainly through the provisioning of information relating to the dissimilarities of their vertical structure.

The majority of these studies integrated lidar altimetry data with multi- or hyper-spectral data from medium to high resolution data for LULC classifications over coastal, grassland, woodland, and urban landscapes while few others evaluated using multiple variables derived using lidar data alone (Table 2, Supp. Info.). These studies indicate considerable improvements in the classification accuracy when lidar data were integrated with either multi- or hyper-spectral data while classification performance using lidar data alone remained poor (Table 2, Supp. Info.). According to these findings confusion in the classification results were mainly evident over the areas characterized by dense tree cover, and increased complexity in vertical arrangement of the canopy layers and was partly due to the presence of understory herbaceous vegetation (Garcia et al. 2011, 
Koetz et al. 2008). Over landscapes characterized by more complex terrain and vegetation (i.e. coastal salt marshes), only marginal improvements in classification accuracies have been achieved when lidar data were integrated (Yang et al. 2010).

Lidar derived vegetation height models have also been used for improving vegetation classifications as well as mapping ground topography. These classifications however indicated relatively poor performances, more specifically over mild slopes and densely vegetated areas. Integration of multiple variables derived using lidar is also a promising approach for mapping and characterizing mixed vegetation (Alexander et al 2015, Collin et al. 2010, Chust et al. 2008, Rosso et al. 2006, Sadro et al. 2007, Yang et al. 2010, Zlinszky et al. 2014). For example, integration of a novel vegetation index (Normalized Difference Lidar Vegetation Index NDLVI) using dual wavelength lidar returned superior results in mapping intertidal marsh vegetation and adjacent coastal areas (Collin et al. 2010). Integration of multiple variables extracted from lidar data (i.e. raw \& filtered intensity, reflectance, point density), lidar derived DEMs and vegetation height models is also a possibility (Alexander et al. 2015, Chust et al. 2008, Zlinszky et al. 2014). As these data layers can provide information relating to differences in landscape as well as vegetation, combination of different layers may improve capability of classification models to separate different habitats.

Lidar intensity data can also be used for improving accuracy of habitat classification within herbaceous land cover (Brennan \& Webster 2006, Chust et al. 2008, Song et al. 2002). Lidar intensity images however, have increased limitations in vegetation applications mainly due to their excessive noise and artifacts caused by sensor scanning that lead to heterogeneous and speckled images (Brennan $\&$ Webster 2006, Song et al. 2002). The excessive noise in intensity data is largely attributed to the angle of reflection and thus, same land cover class may give rise to different intensi- ty values due to changes in angle of reflection alone (Song et al. 2002). In coastal environments, submerged conditions can also introduce noise in lidar intensity values, as water can attenuate near infrared pulses (Hladik et al. 2013). Thus, in coastal environments acquisition of lidar data under low tidal conditions is generally recommended. However, we did not find evidence of any study that evaluated the effects of submerged conditions on the noise.

Over short stature environments, lidar data has been used in LULC classifications to characterize morphology of desert grasslands (Rango et al. 2000), sagebrush vegetation in semi-arid landscapes (Sankey \& Bond 2011, Struetker \& Glenn 2006), and coastal landscapes (Rapinel et al. 2014, Rosso et al. 2006, Sadro et al. 2007). Some of these studies attempted to improve classification accuracies by capturing the changes in vegetation growth over time as reflected in lidar-derived digital surface models of two time periods (Rosso et al. 2006). Even though comparable levels of vegetation penetration during both years were assumed in this approach, differential laser penetration through vegetation canopies can be identified as a major issue in the use of multi-temporal lidar datasets. Integration of multi-spectral signatures in the change detection methodology may help overcome the above limitation. Over the recent past, unavailability of real time data from multi-sensor systems that can generate lidar and passive optical remote sensing data have been one of the biggest limitations for data fusion approaches. However, as the new sensors and systems are being developed, future research will take the advantage of increasing availability of real time multi-sensor data. For example, Goddard's Lidar, Hyperspectral and Thermal (G-LiHT) airborne imager is one such unique development that provides real time multi-sensor data, and thus will contribute to advancing these data fusion concepts and approaches for integrating lidar with hyperspectral as well as thermal remote sensing data (Cook et al. 2013). 
Applications for estimation of vegetation biophysical parameters (height, cover, biomass and carbon)

Once a DTM is derived using lidar data, height above ground surface for any given point can be calculated as the difference between derived DTM and height recorded for each point. Resulting data will provide a three dimensional point cloud representing heights above ground level. This information can then be converted to a vertical point height distribution characterized by various statistics. These statistics are subsequently related to structural properties of vegetation canopies that need to be verified using field reference data (Lefsky et al. 1999, Næsset 2002). These applications have been researched extensively in forestry, while similar applications are reported in short stature herbaceous environments as well. The majority of lidar applications in vegetation studies over non-forested environments concentrated on the estimates of vegetation heights, while only a very few of them evaluated lidar potentials for estimating vegetation cover, canopy shape and volume or biomass.

\section{Vegetation height estimates}

Studies in short stature environments have established empirical relations to predict vegetation height from laser-scanning data (Table 3, Supp. Info.). In general lidar-derived vegetation height estimates over relatively arid grass and shrub land areas agree well with field measurements (Menenti \& Ritchie 1994, Ritchie 1995, Ritchie et al. 1996, Weltz et al. 1994), floodplain grasslands (Assellman et al. 2002, Cobby et al. 2001, Hopkinson et al. 2004, Hopkinson et al. 2005, Straatsma \& Middelkoop 2007), croplands (Davenport et al. 2000, Luo et al. 2016), wetlands (Luo et al. 2014, Wang et al. 2009), and sagebrush dominated rangelands (Glenn et al. 2011, Mitchell et al. 2011, Sankey \& Bond 2011, Streutker \& Glenn 2006). Some of these studies developed regression models for predicting vegetation heights. However these relationships vary significantly (Table 3, Supp. Info.). For example, Cobby et al. (2001) used a log-linear regression, which did not perform well in the study of Hopkinson et al. (2004). Further, the slope of the regression equation of Hopkinson et al. (2004) was significantly higher than that of the Davenport et al. (2000, Table 3, Supp. Info.). In addition, vegetation heights predicted using the derived regression models indicated a poorer detection of vegetation tips, which might attribute to lower vegetation density (Hopkinson et al. 2004). Moreover, these studies were not able to suggest a single laser-derived statistic for predicting vegetation heights or cover (Table 3, Supp. Info.).

Percentiles of laser data have been used extensively to derive vegetation height estimates. The basic assumption in these applications is that the vertical distribution of vegetation canopies is same as the vertical distribution of laser points (Magnussen \& Boudewyn 1998). Consequently, the n-percentile of laser vertical point distribution or the $n$ percentile of laser heights that are derived using the ground elevation as the reference (also referred to as detrended lidar heights) would correspond to the height of vegetation below which $n$ percent of the leaf area occurs. This concept is being further verified in field studies over a range of canopy types and indicated strong correlations between corresponding percentiles of leaf area and laser data (Table 3, Supp. Info.). Standard deviation of lidar heights within a specified local window is also used as a predictor of relatively shorter vegetation over different environments including croplands (Davenport et al. 2000); grasslands of river floodplains (Cobby et al. 2001, Mason \& Scott 2004) and other riparian areas (Hopkinson et al. 2004); wetlands (Luo et al. 2014); and relatively arid grass and shrub land areas (Menenti \& Ritchie 1994). Median value of laser height distribution in a specified local window (Asselman 2002) and a simple multiplier of standard deviation of vertical laser pulse distribution (Cobby et al. 2001, 
Hopkinson et al. 2004, Mason \& Scott 2004, Menenti \& Ritchie 1994) are also suggested as good predictors of vegetation heights. However, limitations of the later variable are identified, more specifically for short vegetation in steep slopes due to tendency of standard deviations to increase with increasing slope regardless of vegetation height (Hodgson et al. 2003). Thus for high slope areas it might be possible to adjust the multiplying factor (slope of the regression model) downwards based on the angle of slope of the DEM (Hodgson et al. 2004). The upper end of laser height distributions (i.e. maximum and $90^{\text {th }}$ percentile) within local windows of varying sizes (i.e. $5 \mathrm{~m} \mathrm{x} 5 \mathrm{~m}$, $3 \mathrm{~m} \times 3 \mathrm{~m}$ ) has been used as a better predictor of vegetation heights over shrub lands (Glenn et al. 2011, Mitchell et al. 2011, Riano et al. 2007) and coastal marshes (Kulawardhana et al. 2014). These findings indicated that local maxima of lidar heights, although superior to standard deviations, consistently underestimated vegetation heights. Further, findings from forestry have shown that lidar metrics relating to the upper end of laser height distributions are highly sensitive to sample point density and morphology of vegetation canopies (Hopkinson et al. 2006, Magnussen \& Boudewyn 1998; Naesset 1997). In particular, when canopy surface height is variable as in the case of most herbaceous vegetation, it is possible that only a single stem of a grass or a shrub canopy will correspond to the maximum lidar height as evidenced in forestry with conical crowns (Lefsky et al. 2007). Thus to capture this increased variation in vegetation heights and canopy surfaces of herbaceous environments, more specifically over grassland and cropland areas, it is important to acquire data with sufficient sampling density. Standard deviation of laser height distributions on the other hand, is a function of the overall distribution of vegetation layers from ground to canopy surfaces. Thus given a sufficient number of laser pulses returning from the area of interest, standard deviation of lidar heights should better capture the variations in vertical structure of vegeta- tion canopy. These findings indicate that the applicability of such variables are largely determined by the interplay between variations of vegetation characteristics (i.e. height and cover) over the given area (and thus within the area of filtering window) and the amount of information available in lidar data (i.e. point density).

Several studies over coastal salt marshes (Wang et al. 2009) and shrub dominant landscapes (Riano et al. 2007) created Digital Surface Models (DSMs), by interpolating lidar variables (i.e. maximum height) within a specified search neighborhood to a continuous surface. Assuming that these DSMs reflect canopy surface elevation, Digital Vegetation Models (DVMs) were then created by subtracting DEM from DSM. Although vegetation heights extracted from resulting DVMs indicated good correspondence with field measured vegetation heights, they did not include much of the information from the topmost surface of the vegetation. Further, relatively large errors in vegetation height estimates were observed for densely vegetated areas, and were partially attributed to poor separation of lidar returns as ground and vegetation returns. Thus some studies used alternative data source/s (i.e. spectral data) along with lidar for correcting vegetation containing pixels in the derived DEMs and thereby improved accuracy in vegetation height estimates (Rango et al. 2000).

Effects of using different filter sizes for filtering specified laser height statistics have also been evaluated (Brown \& Hugenholtz 2011, Kulawardhana et al. 2014, Wang et al. 2009). Theoretically, increasing filter radius increases the likelihood for capturing laser pulses that were fully penetrated the vegetation and reflected by the ground. This will also make it more likely that the returns from near the top of vegetation are captured in the filtering window. However, increasing filter radius beyond a certain threshold can lead to overestimations in vegetation heights, which is largely attributed to missing local topographic variations in the derived DEMs (Brown \& Hugenholtz 
2011). Further, the DEMs created using moving window filtering algorithms are generally characterized by lower spatial resolution than that of raw lidar data and the amount of information lost during this filtering process can be a function of the window size and degree of variation in surface properties (i.e. vegetation heights). Thus given relatively greater variation of vegetation heights within most low stature herbaceous environments, more specifically over grasslands and croplands, appropriate window size/s should be selected with much care, considering variations in terrain and vegetation characteristics as well as the characteristics of the data itself.

Canopy cover, shape, plant density, biomass and carbon estimates

Theoretically, the proportion of lidar returns originating from vegetation canopies and ground surfaces relate to the amount of vegetation cover, and canopy openings, respectively. Based on this rationale, several lidar metrics have been proposed as canopy cover/ vegetation density related variables. These metrics directly relate to the laser penetration properties within vegetation canopies and also known as laser penetration indices. Assuming a direct inverse relationship between laser penetration and the amount of vegetation cover (i.e. decreasing laser penetration with increasing vegetation cover), laser penetration indices estimate vegetation cover as the ratio of vegetation returns to the total number of returns (Evans et al. 2009). Thus a larger ratio implies a higher vegetation density while a small ratio is indicative of the higher canopy openings. Over the recent past an increasing number of studies reported using laser penetration indices for vegetation cover and biomass estimates in short stature environments, more specifically over crop lands (Luo et al. 2016) grassland dominated rangeland environments (Mograbi et al. 2015, Ritchie et al. 1992, Weltz et al. 1994), sagebrush dominated landscapes (Li et al. 2015, Mitchel et al. 2015, Sankey et 186 al. 2010, Struetker \& Glenn 2006), forest understorey (Estornell et al. 2012) and wetlands (Luo et al. 2014, Kulawardhana et al. 2014).

The biggest challenge of using laser penetration indices relates to defining vegetation returns. Typically, the lowest lidar returns are from the ground while anything above that is from vegetation. However, the common approach used in short stature environments is to set a height threshold and define all the returns within a specified window returning from above that height as vegetation returns. This height threshold and the filtering window size should be applied considering sensor limitations for separating laser pulses returning from similar heights, characteristics of vegetation (i.e. amount of canopy openings) and the data (i.e. lidar point density). In short stature environments height thresholds used to define vegetation returns span a wide range from 0 to $>1.5 \mathrm{~m}$. Relatively smaller height thresholds (i.e. $<0.5 \mathrm{~m}$ ) have been used with higher point density of lidar data and sufficient canopy openings to facilitate laser penetration to the ground surfaces (Luo et al. 2014, Luo et al. 2016, Ritchie et al. 1992, Weltz et al. 1994). Only a very few studies evaluated the effects of variable filtering window sizes and lidar point densities on the accuracies of lidar derived cover variables (Luo et al. 2014, 2016). Over shrub dominated ecosystems, insufficient returns from vegetation in particular over heterogeneous cover conditions is one of the major limitations in using laser penetration indices for canopy cover and/ or volume estimates (Li et al. 2015, Mitchel et al. 2015). In general, when sufficient canopy openings are available to allow laser penetration into the ground surfaces, first and last returns are expected to return from the top of vegetation and ground surfaces, respectively. However, canopy cover estimates using only the first returns are also reported (Mitchell et al. 2011, Struetker \& Glenn 2006). Two important issues can be identified in this approach. First, lidar returning from ground surfaces (i.e. ground returns) are assumed to have no vegetation $(0 \%$ cov- 
er) within their footprint whereas lidar returns originated from above the ground surfaces (i.e. non-ground/ vegetation returns) require only a minimal amount of vegetation to generate a return pulse. This in turn, can lead to a bias in non-ground/ vegetation classifications, and tend to overestimate vegetation cover. Second, the exclusion of last returns can largely eliminate representation of bare earth surfaces leading to underestimation of ground surface, and thus overestimation of the amount of vegetation cover. Lidar intensity values can also be used as a measure of vegetation density (Gopfert \& Heipke 2006). This approach is based on the hypothesis that every layer of vegetation decreases the intensity value for following echoes and thereby leads to decreased intensity values over dense vegetation. However, this hypothesis remains true for spectrally homogeneous vegetation layers, and is not applicable for very dense vegetation surfaces that can yield higher intensity values due to poor laser penetration at the canopy surface. Only a few studies in short stature environments evaluated lidar applications for estimating canopy shape, area (Glenn et al. 2011, Mitchell et al. 2011), volume (Estornell et al. 2012, Hopkinson et al. 2005, Li et al. 2015) and Leaf Area Index (Luo et al. 2014, 2016). In general, errors in canopy shape estimates were partially attributed to low point density ( $\mathrm{Li}$ et al. 2015, Luo et al. 2016, Mitchell et al. 2011, 2015). Even though the underestimation of canopy-projected area reported in these studies is substantial, these errors may be corrected by supplementary measurements from spectral data ( $\mathrm{Li}$ et al. 2015, Mitchel et al. 2015) and ground observations.

It is interesting to notice that over the past few years, increasing number of studies reported using lidar derived vegetation height and cover variables for predicting vegetation biomass in short stature environments more specifically, over tall grass dominated rangelands (Mograbi et al. 2015), coastal salt marshes (Kulawardhana et al. 2014, forest understorey (Estornell et al. 2011, 2012), sagebrush dom- inated landscapes ( $\mathrm{Li}$ et al. 2015), and crop lands (Luo et al. 2016). Even though the biomass predictability of these models were poor (as compared to forest biomass predictions), marginal improvements have been reported when lidar data were integrated with vegetation indices derived from multi- or hyper-spectral data (Kulawardhana et al. 2014, Li et al. 2015). Underestimated vegetation heights from lidar data (Kulawardhana et al. 2014, Li et al. 2015) as well as inability of lidar derived cover variables to capture heterogeneous cover conditions (Li et al. 2015) are likely contributors for poor biomass predictability. Thus, improved height and cover detection with increased lidar point density and/ or supplementary measurements from ground observations and spectral data along with improved methods will contribute to improving biomass predictions even in short stature environments.

\section{Errors and accuracies of lidar derived vegetation estimates}

Lidar applications in herbaceous environments report varying levels of accuracies in vegetation height estimates. However, the absolute errors in vegetation height estimates over similar vegetation were comparable (Table 3, Supp. Info.). The majority of these studies identified underestimation of vegetation heights as a common problem in short stature environments. Underestimation of vegetation heights is typically attributed to: laser penetration into vegetation generating return signals from material within the canopy rather than from top of the canopy surfaces (Clark et al. 2004, Gaveau \& Hill 2003, Weltz et al.1994); poor representation of canopy surfaces due to low point density of lidar data (Glenn et al. 2011, Hodgson \& Bresnahan 2004, Mitchell et al. 2011, Straatsma \& Middelkoop 2007, Streutker \& Glenn 2006) and/ sparse vegetation with increased canopy openings (Davenport et al. 2000); overestimation of ground height due to minimal pulse penetration through dense vegetation (Adams \& Chandler 2002, Ander- 
sen et al. 2006, Hodgson \& Bresnahan 2004, Hopkinson et al. 2004, Wang \& Glenn 2008, Weltz et al. 1994); sensor limitations including signal detection thresholds (Wang et al. 2009); limitations in the methods used in separation of ground vs non-ground returns (Rosso et al. 2006); interpolation errors of either one or both of the ground and vegetation surfaces (Assellman, 2002, Hopkinson et al. 2005); or the combined effects of one or more of these factors (Glenn et al. 2011, Kulawardhana et al. 2014). For example, Glenn et al. (2011) attributed sagebrush height errors to the errors in bare ground estimates, vertical accuracy of lidar system, lidar penetration in to the foliage, and insufficient/ missing lidar signals from topmost layers of sagebrush crown. However, the majority of error contribution was due to laser penetration: at least two-thirds of the error was attributed to canopy penetration and/or the lidar missing the top of the sagebrush crown. Similar findings were observed in grassland environments (Asselman 2002) where lidar missed taller plants leading to considerable underestimates of vegetation heights. These findings suggest that in short stature environments, taller plants are too few or too wide apart to be clearly identified by the laser scanner. Further, low point densities of lidar data that increase the likelihood of missing the top of vegetation is also recognized as a major limitation in short stature vegetation (Glenn et al. 2011, Kulawardhana et al. 2014). Thus high point density lidar data is recommended for improving accuracy of vegetation height estimates in herbaceous environments. Several other studies (Cobby et al. 2001, Davenport et al. 2000, Struetker and Glenn 2006) however, recognized vegetation height underestimates as a result of increased canopy openings. To account for high canopy penetration in herbaceous environments, use of vegetation roughness-based adjustment factor (i.e. standard deviation of vegetation returns within each pixel) was thus suggested. Other studies have demonstrated different factors that can poten- tially introduce variable levels of error in lidar derived vegetation height estimates. These include variable sizes of the filtering or interpolation window adapted in deriving vegetation height models (Glenn et al. 2006, Kulawardhana et al. 2014, Mitchel et al. 2011, Sankey \& Bond 2011), variations in terrain slope (Glenn et al. 2006, Hodgson et al. 2005, Hopkinson et al. 2005), or the presence of unfavorable conditions (i.e. presence of surface water, increased soil moisture) during data acquisition that attenuate laser pulses (Hopkinson et al. 2004, Rosso et al. 2006).

Findings of a few studies indicated that errors and accuracies of vegetation cover related estimates (i.e. percent cover, density, canopy shape, volume) using laser penetration indices vary largely across different landscapes/ ecosystems of short stature vegetation. A strong agreement $\left(r^{2}=0.95\right)$ between lidar derived vegetation height distribution and vegetation cover of relatively taller rangeland vegetation (1-3 m), suggests lidar derived height distribution as a good representation of the vertical profile of vegetation cover (Ritchie et al. (1992 \& 1996), while in a similar grassland environment, which was characterized by relatively shorter plants $(<0.3 \mathrm{~m})$, laser measurements consistently overestimated vegetation cover (Weltz et al. 1994). In a salt marsh environment, none of the lidar derived cover measurements (i.e. laser penetration indices) correlated directly with field measured vegetation cover (Kulawardhana et al. 2014). However, lidar derived cover related variables were able to predict $49 \%$ of vegetation cover $\left(r^{2}=0.49\right)$ over sagebrush dominated landscapes with marginal improvements $\left(r^{2}=0.58\right)$ when integrated with spectral data (Mitchel et al. 2015), and thus indicated increased potential of lidar data for estimates of shrub cover.

Similar to the vegetation cover estimates, biomass prediction models using lidar varied largely over different environments (i.e. reported $\mathrm{r}^{2}$ values are within a wide range from 0.33 to 0.93 ). Overall, biomass predictability 
of lidar derived variables remains relatively low as compared to forest biomass predictions using them. However, these biomass prediction models improved at varying levels when integrated with spectral data from multi- or hyperspectral data (Estornell et al. 2012; Kulawardhana et al. 2014; Li et al 2015). Further, these studies, indicated point density of lidar data (Estornell et al 2011, 2012) and vegetation characteristics ( $\mathrm{Li}$ et al. 2015) as key determinants of the accuracies of biomass prediction models. Findings from a salt marsh study (Kulawardhana et al. 2014) indicated that percent root square error of the biomass regression models were $<20 \%$, which is below the error threshold recommended for remote sensing based forest biomass prediction models that should be used repeatedly for the estimation of forest carbon stock changes (Zolkos et al. 2013). These biomass prediction models therefore indicate a greater potential even in these challenging short stature environments.

\section{Concluding remarks and future direc- tions}

Use of lidar in vegetation studies has accelerated rapidly in recent years. While the literature on lidar applications in forestry is rich, relatively lesser applications are reported in short stature non-forest environments. The majority of these studies have concentrated largely on terrain estimates, while a few used lidar derived variables for estimates of vegetation height, cover and biomass. In this review, we identified three broad categories of lidar applications in short stature environments for: 1) estimating terrain elevation; 2) mapping and characterization of landscape and vegetation; and 3) estimating vegetation biophysical parameters (height, cover and biomass). Our discussions focus on their findings, in particular the levels of accuracies and errors reported as well as the limitations and potentials of the methods applied. These studies were scattered across a wide variety of ecosystems, ranging from short stature desert grasslands to shrub dominated woodlands/ scrublands, and were also distributed over different geographic as well as ecological regions. Methodological approaches and algorithms used in the majority of these studies are largely similar to those reported in forested environments. However, several studies introduced novel approaches largely to overcome increased limitations resulting from relatively short and dense vegetation.

Given the increased challenges in these environments, and considering the interplay between vegetation, terrain, and data characteristics in determining the levels of accuracies of lidar derived terrain and vegetation estimates, we recognize that improved understanding on the interactions between laser pulses and vegetation and other ground objects remains crucial for the appropriate use of lidar in these environments. This understanding should result from assessment of laser-beam properties and characteristics of both vegetation and terrain as they collectively govern laser-interactions with vegetation and thus determine the ability of lidar data to discriminate vegetation from ground. Laser beam properties can include temporal pulse width, band width of the detector, and footprint size. Vegetation characteristics can include leaf orientation, plant height, and degree of canopy openings, while slope and terrain irregularities can be the two main terrain characteristics.

Accurate coding of ground vs. non-ground or vegetation returns has been one of the most critical first steps in both vegetation and terrain estimates in these environments. Even though a wide variety of filtering and interpolation algorithms have been applied in deriving DEMs using lidar, there is a considerable conflicting information relating to the appropriateness of these algorithms over various terrain and vegetation cover conditions. For comprehensive evaluation of their applicability under varying terrain and vegetation conditions a rigorous 
comparison of the strengths and weaknesses of these algorithms and filtering methods is necessary. Although several studies evaluated variability of lidar accuracy by land cover, there are no straight forward methods or findings that report expected accuracy levels for specific land cover categories. As laser pulses do not penetrate every layer of the vegetation in a similar way, and as the vegetation influence is affected by the differences in both vegetation structure and composition, understanding vegetation influence on the lidar accuracy across vegetation layers and over different vegetation categories remains increasingly challenging. In general, the accuracy levels of terrain and vegetation estimates can be recognized as a function of a collection of parameters. These include characteristics of vegetation, lidar system and data, terrain, and the conditions that existed during the time of data acquisition.

In non-forested short stature environments, variable levels of improvements in the classification accuracies were reported when lidar data were integrated with data from passive optical remote sensing. Over complex terrain and densely vegetated areas, lidar derived vegetation related variables when used in LULC classification models reported relatively poor performances. However, findings of these studies in general, indicate that the synergy of lidar and optical data improved LULC classifications as compared to using either of these data alone. These findings thus highlight the necessity of developing appropriate classification algorithms to optimize the use of lidar data while recognizing the limitations of each environment pertaining to their vegetation, terrain as well as other site specific conditions, more specifically for complex terrain and densely vegetated landscapes.

The majority of lidar applications in vegetation studies over non-forested environments concentrated on the estimates of vegetation heights and only a very few of them evaluated lidar potentials for estimating vegetation cover, canopy shape, or the biomass. Studies from over a wide variety of ecosystems (i.e. relatively arid grass and shrub land areas, floodplain grasslands, croplands, coastal salt marshes, sagebrush dominated rangelands) indicate a good correspondence between lidar-derived and field-measured vegetation heights. However, consistent underestimates of vegetation heights, in particular over heterogeneous vegetation cover and when lidar point density was low is recognized as one of the major limitations in using lidar for vegetation height as well as biomass predictions. Further, empirical relationships established in these studies to predict vegetation height from lidar data vary significantly. In addition, these studies were not able to suggest a single laser-derived statistic that is capable of predicting vegetation height or the cover. These findings thus indicate that the applicability of such variables are largely determined by the interplay between variations of vegetation height and cover over the given area and the amount of information available in lidar data (i.e. point density). Errors of lidar derived vegetation height, cover and biomass estimates reported in these environments are substantial. These errors however may be corrected by using supplementary data from ground measurements and also by integrating lidar variables with spectral information. These findings thus indicate potentials of lidar even in these complex and increasingly challenging short stature herbaceous environments.

Considering increased challenges in these environments, some of these studies suggested that lidar applications might be limited in short stature, herbaceous vegetation (i.e. grasslands and croplands) and also in younger stands of woody dominated environments. However, with rapid developments in lidar remote sensing techniques and increasing availability of data over different spatial and temporal scales, development of appropriate research methods and lidar remote sensing techniques is of critical importance for further expansion of lidar remote sensing in wider applications. Once 
appropriate methods are established, lidar remote sensing will provide effective techniques with greater potential for replacing laborious field-based measurements in vegetation studies as well as for spatially extending the site specific local scale field measurements so that large areas could be rapidly and accurately surveyed. In addition, given the ecological as well as economic significance of some of these non-forested ecosystems (i.e. rangelands, wetlands, croplands), expansion of research interests into these environments will contribute to furthering our understanding of lidar remote sensing capabilities for the study of important ecosystems, and their products and services. Such an understanding will serve as the basis for implementing appropriate methods and algorithms that can be most suited for the specific conditions that prevail in these challenging and less lidar-exploited ecosystems.

\section{Acknowledgements}

Authors would like to acknowledge constructive feedback received from anonymous reviewers for improving this manuscript. Ms Taimei Harris and Ms. Ashley Acuna, graduate students of Jackson State University Environmental Science program are also acknowledged for their help with proof reading this manuscript.

\section{References}

Adams J., Chandler J. 2002. Evaluation of lidar and medium scale photogrammetry for detecting soft-cliff coastal change. The Photogrammetric Record 17: 405-418. DOI: 10.1111/0031-868X.00195

Alexander C., Deak B., Kania A., Mücke W., Heilmeier H. 2015: Classification of vegetation in an open landscape using full-waveform airborne laserscanner data. International Journal of Applied Earth Observation and Geoinformation 41: 76-87. DOI: 10.1016/j. jag.2015.04.014

Allen-Diaz B. 1996. Rangelands in a changing climate: impacts, adaptations, and mitigation. In: Watson, R.T., Zinyowera, M.C., Moss, R.H. (Eds.), Climate Change
1995. Impacts, Adaptations, and Mitigation of Climate Change: Scientific-Technical Analyses published for the Intergovernmental Panel on Climate Change. Cambridge University Press, Cambridge, UK, 131-158.

Andersen H.-E., Reutebuch S.E., McGaughey R.J. 2006. A rigorous assessment of tree height measurements obtained using airborne lidar and conventional field methods. Canadian Journal of Remote Sensing 32: 355-366. DOI: $10.5589 / \mathrm{m} 06-030$

Asselman N.E.M. 2002. Laser altimetry and hydraulic roughness of vegetation, further studies using ground truth. Delft Hydraulics, Delft, Netherlands.

Baltsavias E.P. 1999. Airborne laser scanning: existing systems and firms and other resources. ISPRS Journal of Photogrammetry and Remote Sensing 54: 164-198. DOI: $10.1016 / \mathrm{S} 0924-2716(99) 00016-7$

Blair J.B., Hofton M.A. 1999. Modeling laser altimeter return waveforms over complex vegetation using high-resolution elevation data. Geophysical Research Letters 26: 2509-2512. DOI: 10.1029/1999GL010484

Bork E.W., Su J.G. 2007. Integrating lidar data and multispectral imagery for enhanced classification of rangeland vegetation: A meta analysis. Remote Sensing of Environment 111: 11-24. DOI: 10.1016/j.rse.2007.03.011

Boudreau J., Nelson R.F., Margolis H.A., Beaudoin A., Guindon L., Kimes D.S. 2008. Regional aboveground forest biomass using airborne and spaceborne lidar in Québec. Remote Sensing of Environment 112: 38763890. DOI: 10.1016/j.rse.2008.06.003

Bowen Z.H., Waltermire R.G. 2002. Evaluation of light detection and ranging (lidar) for measuring river corridor topography. Journal of the American Water Resources Association 38: 33-41. DOI: 10.1111/j.17521688.2002.tb01532.x

Bufton J.L. 1989. Laser altimetry measurements from aircraft and spacecraft. Proceedings of the IEEE 77: 463477. DOI: $10.1109 / 5.24131$

Chassereau J.E., Bell J.M., Torres R. 2011. A comparison of GPS and lidar salt marsh DEMs. Earth Surface Processes and Landforms 36: 1770-1775. DOI: 10.1002/ esp. 2199

Chust G., Galparsoro I., Borja Á., Franco J., Uriarte A. 2008. Coastal and estuarine habitat mapping, using LIDAR height and intensity and multi-spectral imagery. Estuarine, Coastal and Shelf Science 78: 633-643. DOI: 10.1016/j.ecss. 2008.02 .003

Cobby D.M., Mason D.C., Davenport I.J. 2001. Image processing of airborne scanning laser altimetry data for improved river flood modelling. ISPRS Journal of Photogrammetry and Remote Sensing 56: 121-138. DOI: 10.1016/S0924-2716(01)00039-9

Collin A., Long B., Archambault P. 2010. Salt-marsh characterization, zonation assessment and mapping through a dual-wavelength lidar. Remote Sensing of Environment 114: 520-530. DOI: 10.1016/j.rse.2009.10.011

Cook B.D., Nelson R.F., Middleton E.M., Morton D.C., McCorkel J.T., Masek J.G., Montesano P.M. 2013. NASA Goddard's LiDAR, Hyperspectral and Thermal 
(G-LiHT) Airborne Imager. Remote Sensing 5: 40454066. DOI: $10.3390 /$ rs 5084045

Cowen D.J., Jensen J.R., Hendrix C., Hodgson M.E., Schill S.R. 2000. A GIS-assisted rail construction econometric model that incorporates LIDAR data. Photogrammetric Engineering and Remote Sensing 66: 1323-1328.

Davenport I.J., Bradbury R.B., Anderson G.Q.A., Hayman G.R.F., Krebs J.R., Mason D.C., Wilson J.D., Veck N.J. 2000. Improving bird population models using airborne remote sensing. International Journal of Remote Sensing 21: 2705-2717. DOI: $10.1080 / 01431160050110241$

Drake J.B., Dubayah R.O., Clark D.B., Knox R.G., Blair J.B., Hofton M.A., Chazdon R.L., Weishampel J.F., Prince S. 2002. Estimation of tropical forest structural characteristics using large-footprint lidar. Remote Sensing of Environment 79: 305-319. DOI: 10.1016/S00344257(01)00281-4

Dubayah R., Drake J. 2000. Lidar remote sensing for forestry. Journal of Forestry 98: 44-46.

Estornell J., Ruiz L.A., Velázquez-Martí B., Hermosilla T. 2010. Analysis of the factors affecting lidar DTM accuracy in a steep shrub area. International Journal of Digital Earth 4: 521-538. DOI: 10.1080/17538947.2010.533201

Estornell J., Ruiz L.A., Velázquez-Martí B., Fernández-Sarría A.2011. Estimation of shrub biomass by airborne LiDAR data in small forest stands. Forest Ecology and Management 262: 1697-1703. DOI: 10.1016/j. foreco.2011.07.026

Estornell J., Ruiz L.A., Velázquez-Martí B., Hermosilla T. 2012. Estimation of biomass and volume of shrub vegetation using LiDAR and spectral data in a Mediterranean environment. Biomass Bioenergy 46: 710-721. DOI: 10.1016/j.biombioe.2012.06.023

Evans J., Hudak A., Faux R., Smith A.M. 2009. Discrete Return lidar in Natural Resources: Recommendations for Project Planning, Data Processing, and Deliverables. Remote Sensing 1: 776-794. DOI: 10.3390/rs 1040776

García M., Ria-o D., Chuvieco E., Salas J., Danson F.M. 2011. Multispectral and lidar data fusion for fuel type mapping using Support Vector Machine and decision rules. Remote Sensing of Environment 115: 1369-1379. DOI: $10.1016 /$ j.rse.2011.01.017

Gaveau D.L.A., Hill R.A. 2003. Quantifying canopy height underestimation by laser pulse penetration in small-footprint airborne laser scanning data. Canadian Journal of Remote Sensing 29: 650-657. DOI: 10.5589/ $\mathrm{m} 03-023$

Gesch D.B. 2007. The national elevation dataset. In Maune D., (ed.), Digital elevation model technologies and applications: The DEM Users Manual, (2nd ed.). ASPRS, Maryland, pp. 99-118.

Glenn N.F., Spaete L.P., Sankey T.T., Derryberry D.R., Hardegree S.P., Mitchell J.J. 2011. Errors in lidar-derived shrub height and crown area on sloped terrain. Journal of Arid Environments 75: 377-382. DOI: 10.1016/j.jaridenv.2010.11.005

Gopfert J., Heipke C. 2006. Assessment of lidar DTM in coastal vegetated areas. International Archives of Photogrammetry, Remote Sensing, and Spatial Information Sciences 36: 79-85.

Gorte B., Pfeifer N., Elberink S. O. 2005. Height texture of low vegetation in airborne laser scanner data and its potential for DTM correction. International Archives of the Photogrammetry, Remote Sensing and Spatial Information Sciences 36: 150-155.

Harding D.J., Lefsky M.A., Parker G.G., Blair J.B. 2001. Laser altimeter canopy height profiles: methods and validation for closed-canopy, broadleaf forests. Remote Sensing of Environment 76: 283-297. DOI: 10.1016/ S0034-4257(00)00210-8

Hetherington G. 2009. Laser Scanning: data quality, protocols, and general issues. In Heritage G., Large A. (Eds.), Laser scanning for the environmental sciences, John Wiley \& Sons, pp. 82-101. DOI: 10.1002/9781444311952. ch6

Heritage G., Large A. (Eds.). 2009. Laser scanning for the environmental sciences. John Wiley \& Sons.

Hladik C., Schalles J. Alber M. 2013. Salt marsh elevation and habitat mapping using hyperspectral and LIDAR data. Remote Sensing of Environment 139: 318-330. DOI: $10.1016 /$ j.rse.2013.08.003

Hodgson M.E., Bresnahan P. 2004. Accuracy of airborne lidar-derived elevation: empirical assessment and error budget. Photogrammetric Engineering and Remote Sensing 70: 331-340. DOI: 10.14358/PERS.70.3.331

Hodgson M.E., Jensen J., Raber G., Tullis J., Davis B.A., Thompson G., Schuckman K. 2005. An evaluation of lidar-derived elevation and terrain slope in leaf-off conditions. Photogrammetric Engineering \& Remote Sensing 71: 817-823. DOI: 10.14358/PERS.71.7.817

Hodgson M.E., Jensen J.R., Schmidt L., Schill S., Davis B. 2003. An evaluation of lidar- and IFSAR-derived digital elevation models in leaf-on conditions with USGS Level 1 and Level 2 DEMs. Remote Sensing of Environment 84: 295-308. DOI: 10.1016/S00344257(02)00114-1

Hopkinson C., Chasmer L., Lim K., Treitz P., Creed I. 2006. Towards a universal lidar canopy height indicator. Canadian Journal of Remote Sensing 32: 139-152. DOI: $10.5589 / \mathrm{m} 06-006$

Hopkinson C., Chasmer L.E., Sass G., Creed I.F., Sitar M., Kalbfleisch W., Treitz P. 2005. Vegetation class dependent errors in lidar ground elevation and canopy height estimates in a boreal wetland environment. Canadian Journal of Remote Sensing 31: 191-206. DOI: 10.5589/ m05-007

Hopkinson C., Lim K., Chasmer L.E., Treitz P., Creed I.F., Gynan C. 2004. Wetland grass to plantation forest-estimating vegetation height from the standard deviation of lidar frequency distributions. International Archives of Photogrammetry, Remote Sensing and Spatial Information Sciences 36: 8-18.

Jakubauskas M.E., Legates D.R., Kastens J.H. 2001. Harmonic analysis of time-series AVHRR NDVI data. Photogrammetric Engineering and Remote Sensing 67: 
461-470.

James L.A., Watson D.G., Hansen W.F. 2007. Using lidar data to map gullies and headwater streams under forest canopy: South Carolina, USA. Catena 71: 132-144. DOI: $10.1016 /$ j.catena.2006.10.010

Kilian J., Haala N., Englich M. 1996. Capture and evaluation of airborne laser scanner data. International Archives of Photogrammetry and Remote Sensing 31: 383-388.

Koetz B., Morsdorf F., Van der Linden S., Curt T., Allgöwer, B. 2008. Multi-source land cover classification for forest fire management based on imaging spectrometry and LiDAR data. Forest Ecology and Management 256: 263-271. DOI: 10.1016/j.foreco.2008.04.025

Kraus K., Pfeifer N. 1998. Determination of terrain models in wooded areas with airborne laser scanner data. ISPRS Journal of Photogrammetry and Remote Sensing 53: 193-203. DOI: 10.1016/S0924-2716(98)00009-4

Kulawardhana R.W., Popescu S.C., Feagin R.A. 2014. Fusion of lidar and multispectral data to quantify salt marsh carbon stocks. Remote Sensing of Environment 154: 345-357. DOI: 10.1016/j.rse.2013.10.036

Lane S.N. 2000. The measurement of river channel morphology using digital photogrammetry. The Photogrammetric Record 16: 937-961. DOI: 10.1111/0031868X.00159

Lefsky M.A., Harding D., Cohen W.B., Parker G., Shugart H.H. 1999. Surface lidar remote sensing of basal area and biomass in deciduous forests of Eastern Maryland, USA. Remote Sensing of Environment 67: 83-98. DOI: 10.1016/S0034-4257(98)00071-6

Lefsky M.A., Harding D.J., Keller M., Cohen W.B., Carabajal C.C., Del Bom Espirito-Santo F., Hunter M.O., de Oliveira R. 2005. Estimates of forest canopy height and aboveground biomass using ICESat. Geophysical Research Letters 32, L22S02. DOI: 10.1029/2005GL023971

Lefsky M.A., Keller M., Pang Y., De Camargo P.B., Hunter M.O. 2007. Revised method for forest canopy height estimation from Geoscience Laser Altimeter System waveforms. Journal of Applied Remote Sensing 1: 013537. DOI: $10.1117 / 1.2795724$

Li A., Glenn N.F., Olsoy P.J., Mitchell J.J., Shrestha R. 2015. Aboveground biomass estimates of sagebrush using terrestrial and airborne LiDAR data in a dryland ecosystem. Agricultural and Forest Meteorology 213: 138-147. DOI: 10.1016/j.agrformet.2015.06.005

Lim K., Treitz P., Baldwin K., Morrison I., Green J. 2003. Lidar remote sensing of biophysical properties of tolerant northern hardwood forests. Canadian Journal of Remote Sensing 29: 658-678. DOI: 10.5589/m03-025

Lin C., Thomson G., Lo C.S., Yang M.S. 2011. A multi-level morphological active contour algorithm for delineating tree crowns in mountainous forest. Photogrammetric Engineering and Remote Sensing 77: 241249. DOI: 10.14358/PERS.77.3.241

Lin C., Thomson G., Popescu S.C. 2016. An IPCC-Compliant Technique for Forest Carbon Stock Assessment
Using Airborne LiDAR-Derived Tree Metrics and Competition Index. Remote Sensing 8: 528-532. DOI: 10.3390/rs8060528

Lloyd C.D., Atkinson P.M. 2002. Deriving DSMs from lidar data with kriging. International Journal of Remote Sensing 23: 2519-2524. DOI: 10.1080/01431160110097998

Lohani B., Mason D.C. 2001. Application of airborne scanning laser altimetry to the study of tidal channel geomorphology. ISPRS Journal of Photogrammetry and Remote Sensing 56: 100-120. DOI: 10.1016/S09242716(01)00041-7

Luo S., Wang C., Pan F., Xi X., Li G., Xia S. Nie S. 2014. Estimation of wetland vegetation height and leaf area index using airborne laser scanning data. Ecological Indicators 48: 550-559. DOI: 10.1016/j. ecolind.2014.09.024

Luo S., Chen J.M., Wang C., Xi X., Zeng H., Peng D. Li D. 2016. Effects of LiDAR point density, sampling size and height threshold on estimation accuracy of crop biophysical parameters. Optics Express 2411: 1157811593. DOI: $10.1364 /$ OE.24.011578

Magnussen S., Boudewyn P. 1998. Derivations of stand heights from airborne laser scanner data with canopy-based quantile estimators. Canadian Journal of Forest Research 28: 1016-1031. DOI: 10.1139/x98-078

Maling D. H. 1988. Measurements from maps: principles and methods of cartometry. Butterworth-Heinemann.

Mason D.C., Scott T.R. 2004. Remote sensing of tidal networks and their relation to vegetation. In S. Fagherazzi, L. Blum, \& M. Marani (Eds.), Ecogeomorphology of Tidal Marshes. Washinton, DC: American Geophysical Union, Coastal and Estuarine Monograph Series. DOI: 10.1029/ce059p0027

Means J.E., Acker S.A., Harding D.J., Blair J.B., Lefsky M.A., Cohen W.B., Harmon M.E., McKee W.A. 1999. Use of large-footprint scanning airborne lidar to estimate forest stand characteristics in the western cascades of Oregon. Remote Sensing of Environment 67: 298308. DOI: 10.1016/S0034-4257(98)00091-1

Menenti M., Ritchie J.C. 1994. Estimation of effective aerodynamic roughness of Walnut Gulch watershed with laser altimeter measurements. Water Resources Research 30: 1329-1337. DOI: 10.1029/93WR03055

Mirik M., Michels Jr G.J., Kassymzhanova-Mirik S., Elliott N.C. 2007. Reflectance characteristics of Russian wheat aphid (Hemiptera: Aphididae) stress and abundance in winter wheat. Computers and Electronics in Agriculture 57: 123-134. DOI: $10.1016 /$ j.compag.2007.03.002

Mitchell J., Glenn N.F., Sankey T., Derryberry D.R., Anderson M.O., Hruska R.C. 2011. Small-footprint lidar estimations of sagebrush canopy characteristics. Photogrammetric Engineering \& Remote Sensing 77: 521530. DOI: 10.14358/PERS.77.5.521

Mitchell J.J., Shrestha R., Spaete L.P., Glenn N.F. 2015. Combining airborne hyperspectral and LiDAR data across local sites for upscaling shrubland structural information: lessons for HyspIRI. Remote Sensing of En- 
vironment 167: 98-110. DOI: 10.1016/j.rse.2015.04.015 Mograbi P.J., Erasmus B.F.N., Witkowski E.T.F., Asner G.P., Wessels K.J., Renaud M., Knapp D. E., Martin R. E. Main R. 2015. Biomass Increases Go under Cover: Woody Vegetation Dynamics in South African Rangelands. PLoS ONE 10: e0127093. DOI: 10.1371/journal. pone.0127093

Montane J.M., Torres R. 2006. Accuracy assessment of lidar saltmarsh topographic data using RTK GPS. Photogrammetric Engineering and Remote Sensing 72: 961967. DOI: 10.14358/PERS.72.8.961

Montesano P.M., Nelson R.S., Dubayah R.O., Sun G., Cook B.D., Ranson K.J.R, Næsset V., Kharuk V. 2014. The uncertainty of biomass estimates from LiDAR and SAR across a boreal forest structure gradient. Remote sensing of Environment 154: 398-407. DOI: 10.1016/j. rse.2014.01.027

Morris J.T., Sundareshwar P.V., Nietch C.T., Kjerfve B., Cahoon D.R. 2002. Responses of coastal wetlands to rising sea level. Ecology 83: 2869-2877. DOI: 10.1890/0012-9658(2002)083[2869:ROCWTR]2.0. $\mathrm{CO} ; 2$

Mundt J.T., Streutker D.R., Glenn N.F. 2006. Mapping sagebrush distribution using fusion of hyperspectral and lidar classifications. Photogrammetric Engineering \& Remote Sensing 72: 47-54. DOI: 10.14358/ PERS.72.1.47

Mutlu M., Popescu S.C., Stripling C., Spencer T. 2008. Mapping surface fuel models using lidar and multispectral data fusion for fire behavior. Remote Sensing of Environment 112: 274-285. DOI: 10.1016/j. rse.2007.05.005

Næsset E. 2002. Predicting forest stand characteristics with airborne scanning laser using a practical two-stage procedure and field data. Remote Sensing of Environment 80: 88-99. DOI: 10.1016/S0034-4257(01)00290-5

Næsset E., Bjerknes K.O. 2001. Estimating tree heights and number of stems in young forest stands using airborne laser scanner data. Remote Sensing of Environment 78: 328-340. DOI: 10.1016/S0034-4257(01)00228-0

Nelson R., Ranson K.J., Sun G., Kimes D.S., Kharuk V., Montesano P. 2009. Estimating Siberian timber volume using MODIS and ICESat/GLAS. Remote Sensing of Environment 1133: 691-701. DOI: 10.1016/j. rse.2008.11.010

Nelson R., Swift R., Krabill W. 1988. Using airborne lasers to estimate forest canopy and stand characteristics. Journal of Forestry 86: 31-38.

Ni-Meister W., Jupp D. L., Dubayah R. 2001. Modeling lidar waveforms in heterogeneous and discrete canopies. Geoscience and Remote Sensing, IEEE Transactions 399: 1943-1958.

Nilsson M. 1996. Estimation of tree heights and stand volume using an airborne lidar system. Remote Sensing of Environment 56: 1-7. DOI: 10.1016/00344257(95)00224-3

Okin G.S., Roberts D.A., Murray B., Okin W.J. 2001. Practical limits on hyperspectral vegetation discrimina- tion in arid and semiarid environments. Remote Sensing of Environment 77: 212-225. DOI: 10.1016/S00344257(01)00207-3

Petrie G., Toth C.K. 2008. Introduction to laser ranging, profiling, and scanning. Topographic Laser Ranging and Scanning: Principles and Processing. CRC Press/Taylor \& Francis, London, pp. 1-28. DOI: 10.1201/9781420051438.ch1

Pfeifer N., Gorte B., Winterhalder D. 2004. Automatic reconstruction of single trees from terrestrial laser scanner data. In Proceedings of 20th ISPRS Congress, pp. 114-119.

Popescu S.C. 2011. Lidar remote sensing. In Q. Weng (Ed.), Advances in Environmental Remote Sensing: Sensors, Algorithms, and Applications: CRC Press, New York, pp. 57-84. DOI: 10.1201/b10599-5

Popescu S.C., Zhao K., Neuenschwander A., Lin C. 2011. Satellite lidar vs. small footprint airborne lidar: Comparing the accuracy of aboveground biomass estimates and forest structure metrics at footprint level. Remote Sensing of Environment 115: 2786-2797. DOI: 10.1016/j.rse.2011.01.026

Populus J., Barreau G., Fazilleau J., Kerdreux M., L'Yavanc J. 2001. Assessment of the LIDAR topographic technique over a coastal area. In Proceedings of CoastGIS, Vol. 1, pp. 4.

Raber G.T., Jensen J.R., Schill S.R., Schuckman K. 2002. Creation of digital terrain models using an adaptive lidar vegetation point removal process. Photogrammetric Engineering and Remote Sensing 68: 1307-1314.

Rango A., Chopping M., Ritchie J., Havstad K., Kustas W., Schmugge T. 2000. Morphological characteristics of shrub coppice dunes in desert grasslands of Southern New Mexico derived from scanning lidar. Remote Sensing of Environment 74: 26-44. DOI: 10.1016/ S0034-4257(00)00084-5

Rapinel S., Hubert-Moy L. Clément B. 2014. Combined use of LiDAR data and multispectral earth observation imagery for wetland habitat mapping. International Journal of Applied Earth Observation and Geoinformation 37: 56-64. DOI: 10.1016/j.jag.2014.09.002

Reutebuch S.E., McGaughey R.J., Andersen H.-E., Carson W.W. 2003. Accuracy of a high-resolution lidar terrain model under a conifer forest canopy. Canadian Journal of Remote Sensing 29: 527-535. DOI: $10.5589 / \mathrm{m} 03-$ 022

Ria-o D., Chuvieco E., Ustin S.L., Salas J., Rodríguez-Pérez J.R., Ribeiro L.M., Viegas D.X., Moreno J.M., Fernández H. 2007. Estimation of shrub height for fuel-type mapping combining airborne lidar and simultaneous color infrared ortho imaging. International Journal of Wildland Fire 16: 341-348. DOI: 10.1071/ WF06003

Ritchie J.C. 1995. Airborne laser altimeter measurements of landscape topography. Remote Sensing of Environment 53: 91-96. DOI: 10.1016/0034-4257(95)00043-Z

Ritchie J.C., Everitt J.H., Escobar D.E., Jackson T.J., Davis M.R. 1992. Airborne laser measurements of range- 
land canopy cover and distribution. Journal of Range Management 45: 189-193. DOI: 10.2307/4002782

Ritchie J.C., Menenti M., Weltz M.A. 1996. Measurements of land surface features using an airborne laser altimeter: the HAPEX-Sahel experiment. International Journal of Remote Sensing 17: 3705-3724. DOI: 10.1080/01431169608949179

Rosso P.H., Ustin S.L., Hastings A. 2005. Mapping marshland vegetation of San Francisco Bay, California, using hyperspectral data. International Journal of Remote Sensing 26: 5169-5191. DOI: 10.1080/01431160500218770

Rosso P.H., Ustin S.L., Hastings A. 2006. Use of lidar to study changes associated with Spartina invasion in San Francisco Bay marshes. Remote Sensing of Environment 100: 295-306. DOI: 10.1016/j.rse.2005.10.012

Sadro S., Gastil-Buhl M., Melack J. 2007. Characterizing patterns of plant distribution in a southern California salt marsh using remotely sensed topographic and hyperspectral data and local tidal fluctuations. Remote Sensing of Environment 110: 226-239. DOI: 10.1016/j. rse.2007.02.024

Sankey T.T., Bond P. 2011. Lidar-Based Classification of Sagebrush Community Types. Rangeland Ecology \& Management 64: 92-98. DOI: 10.2111/ REM-D-10-00019.1

Sankey T. T., Glenn N., Ehinger S., Boehm A., Hardegree S. 2010. Characterizing western juniper expansion via a fusion of Landsat 5 Thematic Mapper and lidar data. Rangeland Ecology \& Management 63: 514-523. DOI: 10.2111/REM-D-09-00181.1

Schmid K.A., Hadley B.C., Wijekoon N. 2011. Vertical accuracy and use of topographic lidar data in coastal marshes. Journal of Coastal Research 27: 116-132. DOI: 10.2112/JCOASTRES-D-10-00188.1

Sithole G., Vosselman G. 2004. Experimental comparison of filter algorithms for bare-earth extraction from airborne laser scanning point clouds. ISPRS Journal of Photogrammetry and Remote Sensing 59: 85-101. DOI: 10.1016/j.isprsjprs.2004.05.004

Smith L.C. 1997. Satellite remote sensing of river inundation area, stage, and discharge: A review. Hydrological Processes 11: 1427-1439. DOI: 10.1002/(SICI)10991085(199708)11:10<1427::AID-HYP473>3.0.CO;2-S

Song J.H., Han S.H., Yu K., Kim Y.I. 2002. Assessing the possibility of land-cover classification using lidar intensity data. International Archives of Photogrammetry Remote Sensing and Spatial Information Sciences 34: 259-262.

Spaete L.P., Glenn N.F., Derryberry D.R., Sankey T.T., Mitchell J.J., Hardegree S.P. 2011. Vegetation and slope effects on accuracy of a lidar-derived DEM in the sagebrush steppe. Remote Sensing Letters 2: 317-326. DOI: 10.1080/01431161.2010.515267

Steininger M.K. 2000. Satellite estimation of tropical secondary forest above-ground biomass: Data from Brazil and Bolivia. International Journal of Remote Sensing 21: 1139-1157. DOI: 10.1080/014311600210119
Straatsma M., Middelkoop H. 2007. Extracting structural characteristics of herbaceous floodplain vegetation under leaf-off conditions using airborne laser scanner data. International Journal of Remote Sensing 28: 2447 2467. DOI: 10.1080/01431160600928633

Straatsma M.W., Middelkoop H. 2006. Airborne laser scanning as a tool for lowland floodplain vegetation monitoring. In R.S.E.W. Leuven, A.M.J. Ragas, A.J.M. Smits, G. Velde (Eds.), Living Rivers: Trends and Challenges in Science and Management, Springer, Netherlands, pp. 87-103. DOI: 10.1007/1-4020-5367-3_6

Streutker D.R., Glenn N.F. 2006. Lidar measurement of sagebrush steppe vegetation heights. Remote Sensing of Environment 102: 135-145. DOI: 10.1016/j. rse.2006.02.011

Su J., Bork E. 2006. Influence of vegetation, slope and lidar sampling angle on DEM accuracy. Photogrammetric Engineering and Remote Sensing 72: 1265-1274. DOI: 10.14358/PERS.72.11.1265

Su J.G., Bork E.W. 2007. Characterization of diverse plant communities in Aspen Parkland rangeland using lidar data. Applied Vegetation Science 10: 407-416. DOI: 10.1111/j.1654-109X.2007.tb00440.x

Töyrä J., Pietroniro A., Hopkinson C., Kalbfleisch W. 2003. Assessment of airborne scanning laser altimetry (lidar) in a deltaic wetland environment. Canadian Journal of Remote Sensing 29: 718-728. DOI: 10.5589/ m03-040

Vosselman G. 2000. Slope based filtering of laser altimetry data. International Archives of Photogrammetry and Remote Sensing 33: 935-942.

Wang C., Glenn N.F. 2008. A linear regression method for tree canopy height estimation using airborne lidar data. Canadian Journal of Remote Sensing 34: S217-S227. DOI: $10.5589 / \mathrm{m} 08-043$

Wang C., Menenti M., Stoll M.-P., Belluco E., Marani M. 2007. Mapping mixed vegetation communities in salt marshes using airborne spectral data. Remote Sensing of Environment 107: 559-570. DOI: 10.1016/j. rse.2006.10.007

Wang C., Menenti M., Stoll M.-P., Feola A., Belluco E., Marani M. 2009. Separation of ground and low vegetation signatures in lidar measurements of salt-marsh environments. Geoscience and Remote Sensing, IEEE Transactions 47: 2014-2023.

Wehr A., Lohr U. 1999. Airborne laser scanning - an introduction and overview. ISPRS Journal of Photogrammetry and Remote Sensing 54: 68-82. DOI: $10.1016 /$ S0924-2716(99)00011-8

Weltz M.A., Ritchie J.C., Fox H.D. 1994. Comparison of laser and field measurements of vegetation height and canopy cover. Water Resources Research 30: 13111319. DOI: 10.1029/93WR03067

Yang J., Artigas F.J., Wang J. 2010. Mapping salt marsh vegetation by integrating hyperspectral and lidar remote sensing. In Wang Y. (ed.), Remote Sensing of Coastal Environment, CRC Press, pp. 173-190.

Yang X. 2005. Use of lidar elevation data to construct a 
high-resolution digital terrain model for an estuarine marsh area. International Journal of Remote Sensing 26: 5163-5166. DOI: 10.1080/01431160500218630

Zlinszky A., Schroiff A., Kania A., Deák B., Mücke W., Vári Á., Székely B., Pfeifer N., 2014. Categorizing grassland vegetation with full-waveform airborne laser scanning: A feasibility study for detecting Natura 2000 habitat types. Remote Sensing 6: 8056-8087. DOI: 10.3390/rs6098056

Zolkos S.G., Goetz S.J., Dubayah R. 2013. A meta-analysis of terrestrial aboveground biomass estimation using lidar remote sensing. Remote Sensing of Environment 128: 289-298. DOI: 10.1016/j.rse.2012.10.017

\section{Supporting Information}

The online version of the article includes Supporting Information:

Table 1. Elevation estimates using lidar in short stature environments

Table 2. Classification accuracies, data and study area characteristics

Table 3. Vegetation height models using lidar in short stature environments 